\title{
Off-pump coronary artery bypass grafting does not preserve renal function better than on-pump coronary artery bypass grafting: Results of a case-matched study
}

\author{
Elsayed Elmistekawy, MD, ${ }^{\mathrm{a}}$ Vincent Chan, MD, MPH, ${ }^{\mathrm{a}}$ Michael E. Bourke, MD, ${ }^{\mathrm{b}}$ \\ Jean-Yves Dupuis, MD, ${ }^{\mathrm{b}}$ Fraser D. Rubens, MSc, MD, ${ }^{\mathrm{a}}$ Thierry G. Mesana, MD, PhD, ${ }^{\mathrm{a}}$ and \\ Marc Ruel, MD, MPH ${ }^{\mathrm{a}, \mathrm{c}}$
}

Objective: Controversy exists regarding the perioperative renal effects of off-pump versus on-pump coronary artery bypass grafting. Large case-matched and randomized comparisons have shown conflicting results. This study focuses on this clinical controversy.

\begin{abstract}
Methods: We studied 5589 consecutive patients from a single center who underwent off-pump or on-pump coronary artery bypass grafting between 2002 and 2010. All preoperative, intraoperative, and postoperative data were prospectively collected. Patients were matched by using a nearest neighbor matching estimation method for average treatment effects, with bias correction (Stata 11.2, StataCorp, College Station, Tex). The matching characteristics were age, gender, body mass index, hypertension, diabetes, peripheral vascular disease, cerebrovascular disease, left ventricular grade, preoperative serum creatinine, operative priority, and Cardiac Anesthesia Risk Evaluation score.
\end{abstract}

\begin{abstract}
Results: The mean patient age was $64.9 \pm 10.0$ years, and 4387 (78.5\%) were male. Mean calculated preoperative creatinine clearance was $82.0 \pm 32.6 \mathrm{~mL} / \mathrm{min}$. Perioperative mortality was $1.5 \%$ with off-pump coronary artery bypass grafting and $1.7 \%$ with on-pump coronary artery bypass grafting $(P=.6)$. The mean change in creatinine clearance, from the preoperative value to the lowest postoperative value, was $-6.3 \pm 14.1 \mathrm{~mL} / \mathrm{min}$ with off-pump coronary artery bypass grafting versus $-5.0 \pm 15.5 \mathrm{~mL} / \mathrm{min}$ with on-pump coronary artery bypass grafting $(P=.06)$. After matching, patients undergoing off-pump coronary artery bypass grafting had a greater creatinine increase and greater loss of creatinine clearance postoperatively compared with patients undergoing on-pump coronary artery bypass grafting (both $P<.05$ ). Requirements for de novo postoperative dialysis were equivalent at $2.6 \%$ in off-pump coronary artery bypass grafting versus $2.1 \%$ in on-pump coronary artery bypass grafting $(P=.4)$. Median postoperative hospital stay was 8 days in both groups $(P=.8)$.
\end{abstract}

Conclusions: Off-pump coronary artery bypass grafting does not preserve renal function to a greater extent than on-pump coronary artery bypass grafting. In fact, a trend to the reverse exists with no clinically harmful effects. (J Thorac Cardiovasc Surg 2012;143:85-92)

When compared with conventional on-pump coronary artery bypass grafting (CABG), off-pump coronary artery bypass grafting (OPCAB) has been found to be associated, in some but not all studies, with lower rates of perioperative myocardial infarction, stroke, atrial

\footnotetext{
From the Divisions of Cardiac Surgery ${ }^{\mathrm{a}}$ and Cardiac Anesthesiology, ${ }^{\mathrm{b}}$ University of Ottawa Heart Institute, Ottawa, Ontario, Canada; and Department of Epidemiology and Community Medicine, ${ }^{\mathrm{c}}$ University of Ottawa, Ottawa, Ontario, Canada.

Disclosures: Dr Ruel is on the speakers' bureau of Medtronic, Inc. All other authors have nothing to disclose with regard to commercial support.

Drs Elmistekawy and Chan contributed equally to the article.

Read at the 91st Annual Meeting of The American Association for Thoracic Surgery, Philadelphia, Pennsylvania, May 7-11, 2011.

Received for publication May 9, 2011; revisions received July 14, 2011; accepted for publication Sept 26, 2011; available ahead of print Oct 31, 2011

Address for reprints: Marc Ruel, MD, MPH, University of Ottawa Heart Institute 40 Ruskin Street, Suite 3403, Ottawa, Ontario K1Y 4W7, Canada (E-mail: mruel@ ottawaheart.ca).

$0022-5223 / \$ 36.00$

Copyright (c) 2012 by The American Association for Thoracic Surgery

doi:10.1016/j.jtcvs.2011.09.035
}

fibrillation, and infection, and with reduced duration of ventilation, resource use, and intensive care unit and hospital stay. ${ }^{1-3}$

With regard to renal function, data on the effects of OP$\mathrm{CAB}$ versus on-pump $\mathrm{CABG}$ on postoperative renal impairment have been controversial. Some studies indicated that OPCAB was not associated with reduced renal morbidity, ${ }^{4}$ whereas others suggested that OPCAB decreases the risk of renal impairment after bypass surgery. ${ }^{5,6}$ However, available studies thus far did not include a large number of patients or did not allow for comparisons that accounted for important and prospectively captured covariates, which could affect the hemodynamic, inflammatory, and renal outcomes of the patients. ${ }^{7}$

The present study aimed at comparing the renal outcomes of OPCAB with that of on-pump CABG in a large, prospective series. To this end, we used multivariable and nearest neighbor case-matched observational study analyses, by which the outcomes of 5039 patients who underwent 


\section{Abbreviations and Acronyms \\ $\mathrm{CABG}=$ coronary artery bypass grafting \\ CARE $=$ Cardiac Anesthesia Risk Evaluation \\ $\mathrm{OPCAB}=$ off-pump coronary artery bypass}

on-pump CABG were compared with that of 550 contemporary patients who underwent $\mathrm{OPCAB}$.

\section{MATERIALS AND METHODS Patient Groups}

The on-pump CABG group in this study includes 5039 consecutive patients who underwent on-pump, first-time CABG, performed by any 1 of 10 surgeons (with a maximum of 8 surgeons at any one time) at the University of Ottawa Heart Institute, during an 8-year study period from mid-2002 to mid-2010. The OPCAB group includes 550 consecutive patients with coronary artery disease who underwent first-time $\mathrm{OPCAB}$ during the same study period, carried out by the 2 surgeons (of the same 10 aforementioned CABG surgeons) who performed (and still perform) more than $25 \%$ of their coronary bypass caseload off-pump (M.R. and F.D.R.). Patients with cerebrovascular or peripheral vascular disease were preferentially referred to an OPCAB surgeon through the institutional central triage. The ultimate decision to perform OPCAB surgery was made by the operating surgeon considering patient preference, patient comorbidities, and coronary anatomy. All elective, urgent, and emergency coronary bypass operations were included. Patients undergoing redo surgery or patients who underwent concomitant procedures, such as valve repair or replacement, aortic surgery, aneurysm resection, atrial fibrillation surgery, septal defect closure, and others, were excluded from the study, unless the associated procedure resulted from a complication of the index surgery.

Preoperative, operative, and postoperative data were prospectively collected and simultaneously entered into 2 distinct and independent databases, which overlap information and were cross-verified for the purposes of the present study. Furthermore, both databases have been subjected to regular quality audits for accuracy and completeness. All patient data from the present study were de-identified and kept at the research premises; as such, individual patient consent was waived.

\section{Operative Management}

The conducts of the on-pump CABG and OPCAB operations have been extensively described. ${ }^{8}$ All procedures were performed via a median sternotomy incision. Patients undergoing on-pump CABG received heparin to maintain their activated clotting time more than 480 seconds while on cardiopulmonary bypass. During aortic crossclamping, antegrade or retrograde cardioplegia (using cold crystalloid from 2002 to 2004, and cold blood after 2004) was intermittently administered at 20- to 30-minute intervals. Patients undergoing $\mathrm{OPCAB}$ received intravenous heparin to maintain the activated clotting time more than 250 seconds from the termination of conduit harvest to the completion of all anastomoses.

Unless contraindicated, after OPCAB, patients were administered, on the day of the operation, daily enteric-coated acetylsalicylic acid $81 \mathrm{mg}$ and clopidogrel $75 \mathrm{mg}$. Likewise, patients undergoing CABG received enteric-coated acetylsalicylic acid 325 to $650 \mathrm{mg}$ postoperatively, within 6 hours of termination of surgery, and the drug was continued at a dose of $325 \mathrm{mg}$ by mouth daily without clopidogrel. Unless contraindicated, antihypertensives were resumed on the first postoperative day. Patients with a radial artery graft were prescribed a benzodiazepine or dihydropyridine calcium channel blocker for 6 months postoperatively.

No standardized postoperative hydration protocol was used in this study. Intravenous fluids were administered to OPCAB and on-pump CABG cases according to systolic blood pressure, urine output, echocardiographic left ventricular filling, central venous pressure, pulmonary artery diastolic or wedge pressure, body weight, and pulmonary function. Extubated patients who had stable hemodynamic and renal indices were placed on a diuretic protocol.

\section{Outcome Definitions}

Patients were followed for a minimum of 30 days after discharge from the hospital. Death was defined as mortality occurring in hospital at any time during the index hospitalization or within 30 days of operation. Perioperative myocardial infarction consisted of new Q-wave on 12-lead electrocardiogram, creatine kinase-MB, or troponin-T or I elevation above institutional cutoff criteria in effect at the time. Stroke was defined as a permanent new focal neurologic deficit occurring intra- or postoperatively, with focal or lateralizing signs on physical examination and computed tomography confirmation.

With regard to renal outcomes, the preoperative creatinine level used was the latest available laboratory result before surgery. The highest postoperative creatinine corresponded to the highest level recorded postoperatively during the index surgical admission. The creatinine clearance was calculated in a gender-specific manner by using the Cockcroft-Gault formula. ${ }^{9}$ For both preoperative and postoperative creatinine clearance calculations, the weight used corresponded to the last available weight before surgery. The change in creatinine clearance was calculated by subtracting the preoperative creatinine clearance from the postoperative creatinine clearance. Patients who were receiving dialysis preoperatively were not included in the reporting and analyses of preoperative creatinine, postoperative creatinine, and creatinine clearance levels.

\section{Statistical Methods}

For all analyses, the classification of on-pump CABG versus OPCAB took place according to the intention-to-treat principle at the initiation of proximal or distal anastomotic grafting. For instance, patients who were converted from OPCAB to on-pump CABG before the initiation of grafting are considered $\mathrm{CABG}$ cases, and those converted to $\mathrm{CABG}$ after the initiation of proximal or distal grafting are considered OPCAB cases. All conversions from $\mathrm{OPCAB}$ to $\mathrm{CABG}$, with their cause, were prospectively recorded.

Comparisons between the on-pump CABG and OPCAB groups were carried out in Stata 11.2 (StataCorp, College Station, Tex). For each renal outcome of interest, 3 types of analyses were performed: crude (ie, univariable), multivariable regression, and nearest neighbor matching. For univariable comparisons, the central limit theorem was assumed for continuous variables, and these were examined by using an unpaired Student $t$ test. Categoric data were examined with a Fisher exact test. Multivariable comparisons of continuous and categoric renal outcomes used linear or logistic regression, respectively, and included all of the following covariates simultaneously, without the use of an automated selection procedure: age, gender, hypertension, body mass index (except for creatinine clearance outcomes), cerebrovascular disease, peripheral vascular disease, diabetes mellitus, Cardiac Anesthesia Risk Evaluation (CARE) score, ${ }^{10}$ left ventricular grade (1-4), ${ }^{11}$ operative priority, and preoperative creatinine (except for creatinine clearance outcomes). Finally, bias-corrected nearest neighbor matching estimations for the average treatment effect of OPCAB versus on-pump CABG on serum creatinine and creatinine clearance were performed, as described by Abadie and Imbens. ${ }^{12}$ With the use of this technique, all observations from the 5039 patients undergoing CABG were matched to their closest matches in the opposite treatment group, namely, the 550 patients undergoing $\mathrm{OPCAB}$, by allowing each observation to be used as a match more than once if necessary, with the order of matching being irrelevant; this, therefore, provided an estimate of the counterfactual treatment outcome.

All results are reported according to the intent-to-treat principle. Continuous data are expressed as means \pm standard deviation, unless specified 
TABLE 1. Preoperative patient characteristics $(N=5589)$

\begin{tabular}{|c|c|c|c|}
\hline & $\begin{array}{c}\text { CABG } \\
(\mathbf{N}=\mathbf{5 0 3 9})\end{array}$ & $\begin{array}{c}\text { OPCAB } \\
(\mathbf{N}=550)\end{array}$ & $\begin{array}{c}P \\
\text { value }\end{array}$ \\
\hline Age, y & $64.8 \pm 9.9$ & $66.6 \pm 10.8$ & $<.001$ \\
\hline BMI, $\mathrm{kg} / \mathrm{m}^{2}$ & $28.7 \pm 5.0$ & $27.7 \pm 4.9$ & $<.001$ \\
\hline Diabetes mellitus, $\mathrm{n}$ & $1881(37.3 \%)$ & $175(31.8 \%)$ & .01 \\
\hline Hypertension, $\mathrm{n}$ & $3921(77.8 \%)$ & $445(80.0 \%)$ & .1 \\
\hline Men/women, n & $3980 / 1059$ & $407 / 143$ & .005 \\
\hline Cerebrovascular disease, $\mathrm{n}$ & $494(9.8 \%)$ & $91(16.5 \%)$ & $<.001$ \\
\hline Peripheral vascular disease, $\mathrm{n}$ & $747(17.4 \%)$ & $134(24.0 \%)$ & $<.001$ \\
\hline \multicolumn{4}{|l|}{ Left ventricular grade, ${ }^{*} \mathrm{n}$} \\
\hline I & $3415(67.7 \%)$ & $394(71.6 \%)$ & .07 \\
\hline II & $1032(20.4 \%)$ & $106(19.2 \%)$ & \\
\hline III & $482(9.5 \%)$ & $36(6.5 \%)$ & \\
\hline IV & $110(2.1 \%)$ & $4(0.7 \%)$ & \\
\hline \multicolumn{4}{|l|}{ Operative priority, $\mathrm{n}$} \\
\hline Elective & $2676(53.3 \%)$ & $316(57.4 \%)$ & \\
\hline Urgent & $2092(41.5 \%)$ & $221(40.1 \%)$ & .002 \\
\hline Emergency $\leq 24 \mathrm{~h}$ & $112(2.2 \%)$ & $9(1.6 \%)$ & \\
\hline Immediate & $159(0.3 \%)$ & $4(0.7 \%)$ & \\
\hline \multicolumn{4}{|l|}{ CARE score } \\
\hline 1 & $373(7.4 \%)$ & $43(7.8 \%)$ & \\
\hline 2 & $2947(58.4 \%)$ & $308(56.0 \%)$ & .1 \\
\hline 3 & $1632(32.3 \%)$ & $181(32.9 \%)$ & \\
\hline 4 & $18(0.3 \%)$ & $3(0.5 \%)$ & \\
\hline 5 & $69(1.3 \%)$ & $15(2.7 \%)$ & \\
\hline Preoperative $\mathrm{Cr}$ (mg/dL) & $1.14 \pm 0.56$ & $1.27 \pm 1.00$ & $<.001$ \\
\hline Preoperative $\mathrm{CrCl}$ (mL/min) & $82.8 \pm 32.5$ & $74.8 \pm 32.7$ & $<.001$ \\
\hline Preoperative dialysis, $\mathrm{n}$ & $49(1.0 \%)$ & $15(2.7 \%)$ & .001 \\
\hline
\end{tabular}

BMI, Body mass index; CARE, Cardiac Anesthesia Risk Evaluation; $\mathrm{Cr}$, creatinine; $\mathrm{CrCl}$, creatinine clearance. $*$ Left ventricular grade $\mathrm{I}=$ ejection fraction $>50 \%$, grade $\mathrm{II}=$ ejection fraction $35 \%-50 \%$, grade III = ejection fraction $20 \%-4 \%$, grade $\mathrm{IV}=$ ejection fraction $<20 \%$.

otherwise, and discrete data are expressed as numbers (percentage). All tests were 2-tailed, and statistical significance was set at $P<.05$.

\section{RESULTS}

The cohort's mean age was $64.9 \pm 10.0$ years, and 4378 patients were male $(78.5 \%)$. Compared with patients undergoing on-pump CABG, Table 1 shows that patients undergoing OPCAB were older $(66.6 \pm 10.8$ years vs $64.8 \pm$ 9.9 years, $P<.001)$ and more commonly had cerebrovascular $(16.5 \%$ vs $9.8 \%, P<.001)$ and peripheral vascular disease $(24.0 \%$ vs $17.4 \%, P<.001)$ (Table 1$)$. Patients undergoing $\mathrm{OPCAB}$ also had a higher preoperative creatinine level $(1.27 \pm 1.00 \mathrm{mg} / \mathrm{dL}$ vs $1.14 \pm 0.56 \mathrm{mg} / \mathrm{dL}, P<.001)$ and a lower preoperative creatinine clearance $(74.8 \pm 32.7$ $\mathrm{mL} / \mathrm{min}$ vs $82.8 \pm 32.5 \mathrm{~mL} / \mathrm{min}, P<.001)$. Patients undergoing OPCAB received fewer coronary grafts compared with patients undergoing on-pump CABG $(2.2 \pm 0.7$ grafts vs $2.8 \pm 0.6$ grafts, $P<.001$ ).

Seventeen patients undergoing OPCAB were converted to on-pump CABG in this series (Table 2): Five conversions occurred before grafting was initiated and are therefore considered as CABG. Of the 12 conversions that occurred after
TABLE 2. Operative characteristics and postoperative results $(\mathbf{N}=\mathbf{5 5 8 9})$

\begin{tabular}{|c|c|c|c|}
\hline & $\begin{array}{c}\text { CABG } \\
(\mathbf{N}=\mathbf{5 0 3 9})\end{array}$ & $\begin{array}{c}\text { OPCAB } \\
(\mathbf{N}=\mathbf{5 5 0})\end{array}$ & $\begin{array}{c}P \\
\text { value }\end{array}$ \\
\hline No. of grafts (mean) & $2.8 \pm 0.6$ & $2.2 \pm 0.7$ & $<.001$ \\
\hline Conversion to $\mathrm{CPB}, \mathrm{n}$ & 5 & 12 & $\mathrm{n} / \mathrm{a}$ \\
\hline Before grafting, $n$ & $5(2.7 \%)^{*}$ & $(\mathrm{n} / \mathrm{a})^{*}$ & \\
\hline Instability during grafting, $\mathrm{n}$ & $\mathrm{n} / \mathrm{a}$ & 7 & \\
\hline Difficult graftability, $\mathrm{n}$ & $\mathrm{n} / \mathrm{a}$ & 4 & \\
\hline Other, $\mathrm{n}$ & $\mathrm{n} / \mathrm{a}$ & $1 \dagger$ & \\
\hline Return to operating room, $\mathrm{n}$ & $233(4.6 \%)$ & $20(3.6 \%)$ & .3 \\
\hline Perioperative MI, $\mathrm{n}$ & $100(2.0 \%)$ & $10(1.8 \%)$ & .9 \\
\hline \multicolumn{4}{|l|}{ Renal outcomes $\dagger$} \\
\hline Highest postoperative $\mathrm{Cr}(\mathrm{mg} / \mathrm{dL})$ & $1.28 \pm 0.77$ & $1.52 \pm 1.29$ & $<.001$ \\
\hline $\begin{array}{l}\text { Lowest postoperative } \\
\mathrm{CrCl}(\mathrm{mL} / \mathrm{min})\end{array}$ & $77.3 \pm 31.5$ & $67.7 \pm 32.0$ & $<.001$ \\
\hline Change in $\mathrm{Cr}(\mathrm{mg} / \mathrm{dL})$ & $0.14 \pm 0.21$ & $0.25 \pm 0.29$ & .001 \\
\hline Change in $\mathrm{CrCl}(\mathrm{mL} / \mathrm{min})$ & $-5.0 \pm 15.5$ & $-6.3 \pm 14.1$ & .06 \\
\hline De novo postoperative dialysis, $\mathrm{n}$ & $104(2.1 \%)$ & $14(2.6 \%)$ & .4 \\
\hline Stroke, $\mathrm{n}$ & $42(0.8 \%)$ & $2(0.4 \%)$ & .3 \\
\hline Median length of stay, $d$ & 8 & 8 & .8 \\
\hline Death, $n$ & $87(1.7 \%)$ & $8(1.5 \%)$ & .9 \\
\hline \multicolumn{4}{|c|}{$\begin{array}{l}\mathrm{CPB} \text {, Cardiopulmonary bypass; } \mathrm{Cr} \text {, creatinine; } \mathrm{CrCl} \text {, creatinine clearance; } \mathrm{MI} \text {, myo- } \\
\text { cardial infarction; } n / a \text {, not applicable. }{ }^{*} \text { Allocation of } \mathrm{CABG} \text { vs OPCAB took place } \\
\text { according to the intention-to-treat principle, before the initiation of proximal or distal } \\
\text { grafting. Patients who were converted from OPCAB to CABG before the initiation of } \\
\text { grafting are considered CABG cases; patients converted to CABG after the initiation } \\
\text { of proximal or distal grafting are considered OPCAB cases. †Exclude patients on } \\
\text { dialysis preoperatively. }\end{array}$} \\
\hline
\end{tabular}

the initiation of grafting (considered OPCAB in the analyses), 4 were due to difficulty in grafting, 7 were due to hemodynamic instability, and 1 was due to an aortic dissection during tangential clamping with a side-biting clamp, which was successfully repaired on pump with circulatory arrest. There was no significant difference between the 2 groups with respect to rates of mortality, postoperative stroke, myocardial infarction, return to the operating room, and ICU or hospital length of stay.

Univariable crude analyses indicated that OPCAB was postoperatively associated with a higher serum creatinine $(1.52 \pm 1.29 \mathrm{mg} / \mathrm{dL}$ vs $1.28 \pm 0.77 \mathrm{mg} / \mathrm{dL}, P<.001)$, lower creatinine clearance $(67.7 \pm 32.0 \mathrm{~mL} / \mathrm{min}$ vs $77.3 \pm 31.5$ $\mathrm{mL} / \mathrm{min}, P<.001$ ), and greater increase in serum creatinine preoperatively to postoperatively $(0.25 \pm 0.29$ vs $0.14 \pm$ $0.21, P=.001)$ compared with on-pump CABG (Table 2). However, unadjusted analyses did not show a significant statistical difference between the 2 groups in the change in creatinine clearance preoperatively to postoperatively $(P=.06)$ or in the need for de novo postoperative dialysis $(P=.4)$.

On multivariable analyses, linear regression models inclusive of all terms enumerated in Table 3 showed that older age, female gender, higher body mass index, higher creatinine preoperatively, peripheral vascular disease, operative priority, higher CARE score, and OPCAB (vs CABG) 
TABLE 3. Multivariable predictors of renal outcomes

\begin{tabular}{lccc}
\hline & $\begin{array}{c}\text { Change in Cr } \\
\text { (weighted effect } \pm \text { SE; mg/dL) }\end{array}$ & $\begin{array}{c}\text { Change in CrCl } \\
\text { (weighted effect } \pm \text { SE; mL/min) }\end{array}$ & $\begin{array}{c}\text { De novo postoperative } \\
\text { dialysis }(\mathbf{O R} \pm \text { SE) }\end{array}$ \\
\hline Age, per year & $0.002 \pm 0.004(<0.001)^{*}$ & $0.003 \pm 0.02(0.9)$ & $1.05 \pm 0.01(<0.001)^{*}$ \\
BMI, per kg/m ${ }^{2}$ & $0.008 \pm 0.009(<0.001)^{*}$ & $-0.69 \pm 0.04(<0.001)^{*}$ & $1.06 \pm 0.02(0.001)^{*}$ \\
Cerebrovascular disease, if present & $-0.011 \pm 0.001(0.4)$ & $-0.04 \pm 0.69(0.9)$ & $1.8 \pm 0.5(0.03)^{*}$ \\
Diabetes mellitus, if present & $-0.012 \pm 0.009(0.2)$ & $0.81 \pm 0.43(0.06)^{*}$ & $2.4 \pm 0.5(<0.001)^{*}$ \\
Female gender, if present & $-0.033 \pm 0.010(<0.001)^{*}$ & $3.5 \pm 0.5(<0.001)^{*}$ & $1.5 \pm 0.3(0.07)$ \\
Hypertension, if present & $0.022 \pm 0.011(0.04)^{*}$ & $-2.0 \pm 0.5(<0.001)^{*}$ & $1.2 \pm 0.4(0.6)$ \\
Peripheral vascular disease, if present & $0.052 \pm 0.012(<0.001)^{*}$ & $-1.7 \pm 0.6(0.003)^{*}$ & $1.4 \pm 0.3(0.2)$ \\
Preoperative Cr, per mg/dL & $-0.048 \pm 0.012(<0.001)^{*}$ & $10.2 \pm 0.6(<0.001)^{*}$ & $1.5 \pm 0.1(<0.001)^{*}$ \\
Left ventricular grade, per grade increase & $0.020 \pm 0.005(<0.001)^{*}$ & $-0.75 \pm 0.28(0.007)^{*}$ & $1.2 \pm 0.1(0.1)$ \\
Operative priority, per unit increase & $0.028 \pm 0.006(<0.001)^{*}$ & $-1.4 \pm 0.3(<0.001)^{*}$ & $1.9 \pm 0.2(<0.001)^{*}$ \\
CARE score, per unit increase & $0.049 \pm 0.007(<0.001)^{*}$ & $-2.1 \pm 0.4(<0.001)^{*}$ & $1.6 \pm 0.2(0.001)^{*}$ \\
Surgeon $\dagger$ & $3.87-5.88(0.001)^{*}$ & -3.21 to $-2.23(<0.001)^{*}$ & $0.64-1.19(0.7)$ \\
OPCAB vs CABG & $0.05 \pm 0.014(<0.001)^{*}$ & $-2.6 \pm 0.6(<0.001)^{*}$ & $0.9 \pm 0.3(0.8)$ \\
\hline
\end{tabular}

$C A R E$, Cardiac Anesthesia Risk Evaluation; $\mathrm{Cr}$, creatinine; $\mathrm{CrCl}$, creatinine clearance; $S E$, standard error. $P$ values are shown in parentheses below the mean effect or odds ratio. *Statistically significant $P$ value. $\nmid$ Range of coefficients when considering exclusion of any one of the 10 different surgeons in separate multivariable models. The lowest $P$ value is shown in parentheses.

were predictive of a greater increase in creatinine and a greater decrease in creatinine clearance postoperatively. However, there was no independent impact of performing OPCAB versus on-pump CABG on the need for de novo dialysis postoperatively, as revealed by logistic regression.

When comparing matched OPCAB and on-pump CABG cases by using a nearest neighbor matching method, OP$\mathrm{CAB}$ remained associated with a greater increase in postoperative creatinine (by $0.05 \pm 0.02 \mathrm{mg} / \mathrm{dL}, P=.007$ ) and a greater decrease in creatinine clearance (by $-2.1 \pm 0.8$ $\mathrm{mL} / \mathrm{min}, P=.007)$ postoperatively, when compared with CABG (Table 4).

Finally, when the independent effects of OPCAB versus $\mathrm{CABG}$ on renal outcomes were analyzed according to 4 classes of preoperative renal function (Figure 1), there was no trend suggestive of either therapy being significantly better than the other within threshold-specific levels of preexisting renal function.

\section{DISCUSSION}

Postoperative renal dysfunction is a common and serious complication of cardiac surgery. It is associated with a longer

TABLE 4. Nearest neighbor matching estimation of effects of off-pump versus on-pump coronary artery bypass on postoperative renal indices*

\begin{tabular}{lccc}
\hline & $\begin{array}{c}\text { Weighted effect } \pm \text { SE of } \\
\text { OPCAB vs CABG }\end{array}$ & 95\% CI & $\boldsymbol{P}$ value \\
\hline Change in $\mathrm{Cr}(\mathrm{mg} / \mathrm{dL})$ & $0.05 \pm 0.02$ & $0.01-0.08$ & .007 \\
Change in $\mathrm{CrCl}(\mathrm{mL} / \mathrm{min})$ & $-2.1 \pm 0.8$ & -3.7 to -0.6 & .007 \\
\hline
\end{tabular}

$C I$, Confidence interval; $\mathrm{Cr}$, creatinine; $\mathrm{CrCl}$, creatinine clearance; $S E$, standard error. *The bias-adjusted variables used for nearest neighbor matching were preoperative creatinine level, age, body mass index, and operative priority. The variables used for exact matching were gender, cerebrovascular disease, peripheral vascular disease, left ventricular grade, diabetes mellitus, hypertension, and CARE score. intensive care unit and hospital stay in addition to a higher perioperative mortality. ${ }^{13-16}$ Emerging evidence suggests that even small increases in serum creatinine after cardiac surgery may be associated with poorer survival. ${ }^{17}$

Several preoperative risk factors have been associated with an increased risk of acute renal failure after CABG. These include female gender, advanced age, reduced left ventricular function or presence of congestive heart failure, diabetes mellitus, peripheral vascular disease, the need for emergency surgery, and elevated preoperative serum creatinine. ${ }^{18,19}$ Intraoperative risk factors for acute renal injury include prolonged cardiopulmonary bypass and aortic crossclamp times ${ }^{13}$; in this regard, inadequate or nonpulsatile renal perfusion, macro- and microembolic loads on the renal vasculature, and the inflammatory response to cardiopulmonary bypass have all been implicated as potential etiologic factors for postoperative renal dysfunction and renal failure. ${ }^{4,13}$

Although OPCAB removes some of the intraoperative risk factors associated with cardiopulmonary bypass, the relative benefits of OPCAB on renal function have been a controversial issue in the cardiac surgical literature. ${ }^{4-6,20}$ The present study reveals that OPCAB is not protective of renal function and seems to be associated with a small, but statistically significant increase in postoperative serum creatinine and decrease in creatinine clearance. The development of renal dysfunction after CABG is multifactorial, and many perioperative factors that may lead to renal dysfunction are independent of the technique of revascularization. Although the patients undergoing OPCAB in our study presented more risk factors for the development of renal dysfunction than those undergoing on-pump $\mathrm{CABG}$, the independent response to OPCAB also trended toward being unfavorable. It is possible that 
Change in Serum Creatinine Level from Preoperative to Postoperative, OPCAB versus CABG

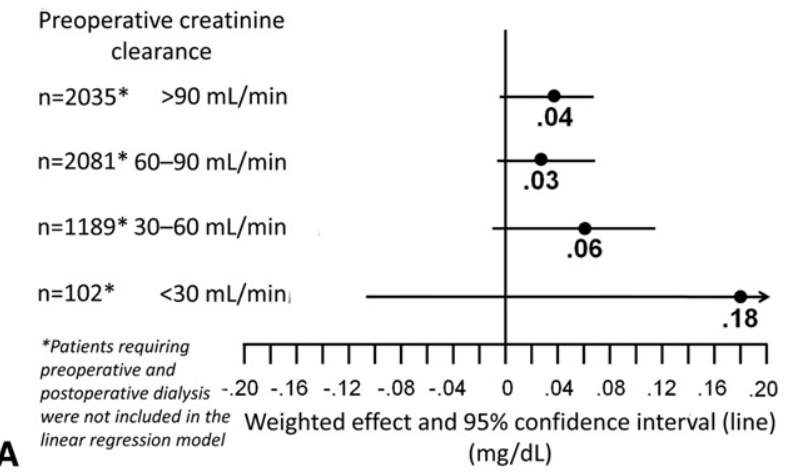

Change in Creatinine Clearance from Preoperative to Postoperative, OPCAB versus CABG

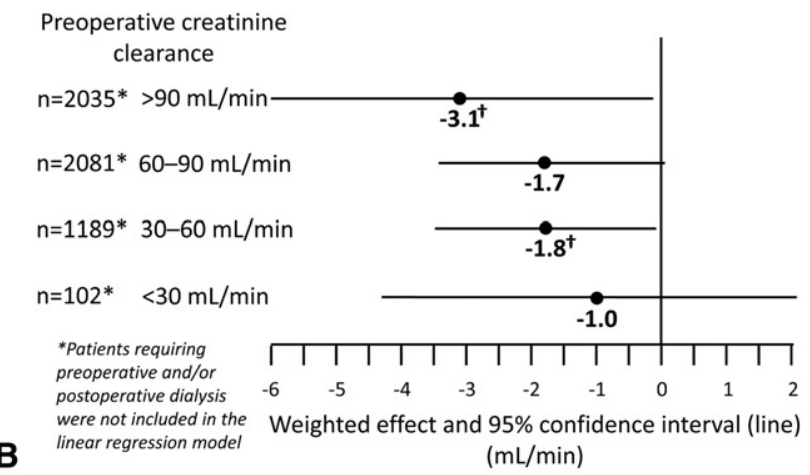

Postoperative Dialysis in Patients Not Requiring Dialysis Preoperatively, OPCAB versus CABG

$\begin{gathered}\text { Preoperative creatinine } \\ \text { clearance }\end{gathered}$
$\mathrm{n}=2045 \quad>90 \mathrm{~mL} / \mathrm{min}$
$\mathrm{n}=2112 \quad 60-90 \mathrm{~mL} / \mathrm{min}$
$\mathrm{n}=1244 \quad 30-60 \mathrm{~mL} / \mathrm{min}$
$\mathrm{n}=124 \quad<30 \mathrm{~mL} / \mathrm{min}$

\section{C}

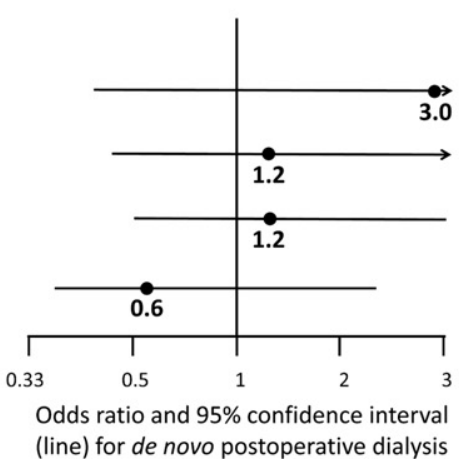

FIGURE 1. Effects of OPCAB versus on-pump CABG on renal outcomes according to the degree of preoperative renal dysfunction. The weighted effect and confidence interval for the change in serum creatinine (A) and creatinine clearance (B) preoperatively to postoperatively. C, Odds ratio and confidence interval of postoperative dialysis in patients who were not requiring dialysis preoperatively. $\dagger P<.05$. OPCAB, Off-pump coronary artery bypass; $C A B G$, coronary artery bypass grafting.

the effects of a different type of surgical trauma, different use of anesthetic drugs, different vasoactive and inotropic medications used, and lesser perioperative intravenous volume loading in $\mathrm{OPCAB}$ versus on-pump $\mathrm{CABG}$ cases may make the former group more at risk of subclinical nephrotoxicity, beyond the advantages expected to be conferred by the avoidance of cardiopulmonary bypass. Furthermore, the use of a cell saver device, suctioningbased stabilizers, and other off-pump tools may inherently induce some degree of inflammatory response. ${ }^{21} \mathrm{OPCAB}$ may induce short, transient periods of hypoperfusion that compromise both cardiac output and renal perfusion during exposure of target vessels, which could be a contributing factor in the development of postoperative renal failure. $^{4,13,22}$

\section{Previous Related Work}

Our results are in agreement with those of Asimakopoulos and colleagues, ${ }^{23}$ in their retrospective study of 704 consecutive patients. Of these patients, 404 had undergone OPCAB and 300 had undergone on-pump CABG. These authors found no statistically significant difference in postoperative hemodialysis rates between groups and noted similar postoperative changes in creatinine clearance. Tang and colleagues ${ }^{24}$ prospectively randomized 40 lowrisk patients with normal preoperative cardiac and renal functions awaiting elective CABG. They found significant and similar levels of injury to renal tubules and glomeruli after OPCAB or CABG. ${ }^{24}$ In a retrospective study that included 690 patients undergoing primary elective coronary bypass (OPCAB, $\mathrm{N}=55$; $\mathrm{CABG}, \mathrm{N}=635$ ), Gamoso and colleagues ${ }^{5}$ did not find that $\mathrm{OPCAB}$ significantly reduced perioperative renal dysfunction compared with CABG. In a meta-analysis of 37 randomized trials (3369 patients) of OPCAB versus CABG performed by Cheng and colleagues, ${ }^{3}$ there was no significant difference between the 2 techniques regarding renal dysfunction. In a retrospective study of 2943 patients with multivessel surgical coronary disease, Di Mauro and colleagues ${ }^{25}$ found that OPCAB may play a renoprotective role and provides better early and late outcomes in patients with normal preoperative creatinine; however, when the preoperative creatinine was abnormal, the surgical strategy did not seem to have any influence, and the occurrence of renal failure impaired early and long-term mortality equally, regardless of choice of operative strategy. In a randomized trial that included 2203 patients scheduled for elective or urgent CABG and randomized to $\mathrm{CABG}$ or OPCAB, Shroyer and colleagues ${ }^{26}$ found no statistical significant benefit of OPCAB on renal end points. OPCAB had a worse composite outcome incidence than CABG with respect to all-cause mortality, repeat revascularization, or nonfatal myocardial infarction at 1 year follow-up. Ascione and colleagues ${ }^{27}$ and Loef and colleagues ${ }^{28}$ reported that OPCAB has renal protective effects, but although their studies were prospective, they included only a small number of healthy patients without renal impairment or major comorbidities. 
In a recently published meta-analysis that included 22 randomized controlled trials, with a total number of patients of 4819 , Seabra and colleagues ${ }^{7}$ reported that when compared with CABG, OPCAB was associated with $40 \%$ lower odds for postoperative acute renal injury $(P=.003)$ and a nonsignificant $33 \%$ reduction in the odds of requiring dialysis; OPCAB was not associated with a decrease in mortality. Although this meta-analysis included 22 trials, it is limited by the following factors: heterogeneous definitions of acute renal injury (some trials did not describe the criteria used for definition of acute renal injury), more than half of these trials included less than 100 patients, none of these trials included emergency revascularization (most of the trials even did not include urgent operations), and the trials did not routinely report comorbidities. Furthermore, when excluding the smaller trials (with the highest reported incidence of renal injury) from this meta-analysis, the statistical significance of the pooled acute renal injury outcome was lost.

\section{Limitations}

Although the present study is a large series involving prospectively collected data on all patients who met inclusion criteria for analysis at our center, it still has the limitation of being a retrospective analysis and a single-center experience. All efforts were made to account for confounders, but it is also possible that unsuspected comorbidities, institutional, technical, or biological factors may have influenced results. For example, the renal responses to surgery may have been exaggerated in patients with more comorbidities. Because these patients also tended to undergo OPCAB surgery, effect modification may be observed. Also, patients undergoing $\mathrm{OPCAB}$ had fewer coronary grafts than those undergoing on-pump $\mathrm{CABG}$, which is in keeping with previous work. ${ }^{26}$ Although no difference in the incidence of perioperative myocardial infarction, perioperative stroke, prolonged hospital stay, or death was observed between groups, the difference in the number of grafts is important. As such, the number of coronary grafts was included as a covariate in each of the multivariable models.

\section{CONCLUSIONS}

Notwithstanding the aforementioned limitations, our study reveals, in a large cohort, that OPCAB does not preserve renal function to a greater extent than on-pump CABG. In fact, a trend to the reverse exists with no clinically harmful effects. On the basis of these findings, although there may be several other benefits of performing OPCAB in some patients, we believe that improved renal preservation compared with CABG does not seem to constitute one of them, and that more research as to the mechanism explaining this lack of protective effect, as well as toward possibly overcoming it with renal protective strategies or adjuvants, is warranted.

\section{References}

1. Sedrakyan A, Wu AW, Parashar A, Bass EB, Treasure T. Off-pump surgery is associated with reduced occurrence of stroke and other morbidity as compared with traditional coronary artery bypass grafting: a meta-analysis of systematically reviewed trials. Stroke. 2006;37:2759-69.

2. Puskas J, Cheng D, Knight J, Angelini G, DeCannier D, Diegeler A, et al. Offpump versus conventional coronary artery bypass grafting: a meta-analysis and consensus statement from the 2004 ISMICS Consensus Conference. Innovations. 2005; 1:3-27.

3. Cheng DC, Bainbridge D, Martin JE, Novick RJ. Does off-pump coronary artery bypass reduce mortality, morbidity and resource utilization when compared with conventional coronary artery bypass? A meta-analysis of randomized trials. Anesthesiology. 2005;102:188-203.

4. Schwann NM, Horrow JC, Strong MD, Chamchad D, Guerraty A, Wechsler AS. Does off-pump coronary artery bypass reduce the incidence of clinically evident renal dysfunction after multivessel myocardial revascularization? Anesth Analg. 2004;99:959-64.

5. Gamoso MG, Phillips-Bute B, Landolfo KP, Newman ME, Stafford-Smith M. Off-pump versus on-pump coronary artery bypass surgery and postoperative renal dysfunction. Anesth Analg. 2000;91:1080-4.

6. Hayashida N, Teshima H, Chihara S, Tomoeda H, Takaseya T, Hiratsuka R, et al. Does off-pump coronary artery bypass grafting really preserve renal function? Circ J. 2002;66:921-5.

7. Seabra VF, Alobaidi S, Balk EM, Poon AH, Jaber BL. Off-pump coronary artery bypass surgery and acute kidney injury: a meta-analysis of randomized controlled trials. Clin J Am Soc Nephrol. 2010;5:1734-44.

8. Chan V, Sellke FW, Ruel M. Coronary artery bypass grafting. In: Sellke FW, del Nido P, Swanson SJ, eds. Sabiston and Spencer's Surgery of the Chest. 8th ed. Philadelphia, PA: Elsevier Science; 2010. p. 1367-96.

9. Cockcroft DW, Gault MH. Prediction of creatinine clearance from serum creatinine. Nephron. 1976;16:31-41.

10. Dupuis JY, Wang F, Nathan H, Lam M, Grimes S, Bourke M. The cardiac anesthesia risk evaluation score: a clinically useful predictor of mortality and morbidity after cardiac surgery. Anesthesiology. 2001;94:194-204.

11. Ruel M, Al-Faleh H, Kulik A, Chan KL, Mesana TG, Burwash IG. Prosthesis-patient mismatch after aortic valve replacement predominantly affects patients with preexisting left ventricular dysfunction: effect on survival, freedom from heart failure, and left ventricular mass regression. J Thorac Cardiovasc Surg. 2006; 131:1036-44.

12. Abadie A, Imbens GW. Large sample properties of matching estimators average treatment effects. Econometrica. 2006;74:235-67.

13. Mangano CM, Diamondstone LS, Ramsay JG, Aggarwal A, Herskowitz A, Mangano DT. Renal dysfunction after myocardial revascularization: risk factors, adverse outcomes, and hospital resource utilization. Ann Intern Med. 1998;128: 194-203.

14. Zanardo G, Michielon P, Paccagnella A, Rosi P, Calo M, Salandin V, et al. Acute renal failure in the patient undergoing cardiac operation: Prevalence, mortality rate, and main risk factors. J Thorac Cardio Vasc Surg. 1994;107:1489-95.

15. Lok CE, Austin PC, Wanh H, Tu JV. Impact of renal insufficiency on short- and long-term outcomes after cardiac surgery. Am Heart J. 2004;148:430-8.

16. Bove T, Calabro MG, Landoni G, Aletti G, Marino G, Crescenzi G, et al. The incidence and risk of acute renal failure after cardiac surgery. $J$ Cardiothorac Vasc Anesth. 2004;18:442-5.

17. Ooi JSM, Abdul Rahaman MR, Sha SA, Dimon MZ. Renal outcome following on- and off-pump coronary artery bypass graft surgery. Asian Cardiovasc Thorac Ann. 2008;16:468-72.

18. Antunes PE, Prieto D, Ferrao de Oliveira J, Antunes MJ. Renal dysfunction after myocardial revascularization. Eur J Cardiothorac Surg. 2004;25:597-604.

19. Thakar CV, Arrigain S, Worley S, Yared JP, Paganini EP. A clinical score to predict acute renal failure after cardiac surgery. J Am Soc Nephrol. 2005; 16: $162-8$.

20. Dybdahl B, Wahba A, Haaverstad R, Kirkeby-Garstad I, Kierulf P, et al. Onpump versus off-pump coronary artery bypass grafting: more heat shock protein 70 is released after on-pump surgery. Eur J Cardiothorac Surg. 2004;25:985-92.

21. Prondzinsky R, Knüpfer A, Loppnow H, Redling F, Lehmann DW, Stabenow I, et al. Surgical trauma affects the proinflammatory status after cardiac surgery to 
a higher degree than cardiopulmonary bypass. J Thorac Cardiovasc Surg. 2005; 129:760-6.

22. Watter MPR, Ascione R, Ryder IG, Ciulli F, Pitsis AA, Angelini GD. Haemodynamic changes during beating heart coronary surgery with the 'Bristol Technique'. Eur J Cardiothorac Surg. 2001;19:34-40.

23. Asimakopoulos G, Karagounis AP, Valencia O, Alexander N, Howlader M, Sarsam MA, et al. Renal function after cardiac surgery off- versus on-pump coronary artery bypass: analysis using the Cockroft-Gault formula for estimating creatinine clearance. Ann Thorac Surg. 2005;79:2024-31.

24. Tang AT, Knott J, Nanson J, Hsu J, Haw MP, Ohri SK. A prospective randomized study to evaluate the renoprotective action of beating heart coronary surgery in low risk patients. Eur J Cardiothorac Surg. 2002;22:118-23.

25. Di Mauro M, Gagliardi M, Iacò AL, Contini M, Bivona A, Bosco P, et al. Does off-pump coronary surgery reduce postoperative acute renal failure? The importance of preoperative renal function. Ann Thorac Surg. 2007;84:1496-502.

26. Shroyer AL, Grover FL, Hattler B, Collins JF, McDonald GO, Kozora E, et al. Veterans Affairs Randomized On/Off Bypass (ROOBY) Study Group. Onpump versus off-pump coronary-artery bypass surgery. N Engl J Med. 2009; 361:1827-37.

27. Ascione R, Lloyd CT, Underwood MJ, Gomes WJ, Angelini GD. On-pump versus off-pump coronary revascularization: evaluation of renal function. Ann Thorac Surg. 1999;68:493-8.

28. Loef BG, Epema AH, Navis G, Ebels T, Van Oeveren W, Henning RH. Off-pump coronary revascularization attenuates transient renal damage compared with on-pump coronary revascularization. Chest. 2002;121:1190-4.

\section{Discussion}

Dr Marc Moon (St Louis, Mo). The on-pump versus off-pump debate has been going on for more than a decade, and we really aren't reaching any resolution anytime soon. Although your study demonstrated no difference in the incidence of renal dysfunction, there was a study yesterday [Presented by Lemma M, et al. On-pump vs off-pump coronary artery bypass surgery in highrisk patients: operative results of a prospective randomized trial (on-off study).] that showed the opposite result, and I think most of the studies have been one way or the other and haven't come to a strong conclusion.

I am always impressed when I show up in the intensive care unit the day after surgery and see 2 patients in 2 beds next to each other, and you can't tell which one had off-pump and which one had onpump surgery. The only consistent finding in most of the studies has been a decrease in the transfusion requirements in off-pump surgery, although in a center that uses strict blood conservation techniques, the difference may be fairly minimal.

I would like to ask you a couple of questions about your study. One is this matching technique that you used. You didn't really give us much detail on that. That is a bit usual; it wasn't a propensity match. Maybe you can get a bit into the statistical analysis of that.

Second, your OPCAB cases were substantially sicker, it appeared, than the on-pump CABG cases. Do you think the matching or the multivariate analysis you used can really tease out robustly the differences that may be intrinsic in those 2 different groups of patients?

On the basis of your findings, what technique does your center recommend for these patients undergoing off-pump versus on-pump surgery, and does it depend on the subgroup of patients who is undergoing operation or is it just surgeon dependent on what he or she is most comfortable which, which is what my feelings are?

Dr Elmistekawy. In response to your first question, we used a bias-corrected nearest neighbor matching estimation for average treatment. This technique has been mostly used in economics, and the 5309 patients undergoing on-pump CABG were matched closest to matches in the opposite treatment group, namely, the 550 patients undergoing OPCAB, by allowing each observation to be used as a match more than once if necessary, with the order of matching being irrelevant; this, therefore, provided an estimate of the counterfactual treatment outcome. It is important to note that some variables were specified in the model to be matched exactly, such as gender, cerebrovascular disease, and left ventricular grade, whereas others, such as age, body mass index, and preoperative creatinine, were matched to their nearest neighbor. We think that is used in economics with good validity, and it can also give us a good idea about the average treatment with bias correction.

For your second question, yes, this study included sicker patients undergoing $\mathrm{OPCAB}$, and these sicker patients may have had a different biological response to perioperative stress and be more prone to have renal dysfunction after surgery. But we did both a multivariable regression analysis and this matching analysis, trying to get out all of the confounders, by including all of the major factors that can affect the renal outcome in those patients.

In our center, the choice of on-pump versus off-pump technique is influenced by many factors: number one, patient characteristics, such as the presence of ascending aortic disease and coronary anatomy; number two, patient preference, such as if the patient asks for $\mathrm{OPCAB}$, or the cardiologist referral, which also is a factor in the selection of on-pump CABG versus OPCAB.

Dr Moon. We can safely conclude that these days the most appropriate thing is for the surgeon to do the operation he or she is most comfortable with.

Dr Lokeswara Sajja (Hyderabad, India). I congratulate Dr Elmistekawy for a good presentation, and I have a comment to make and a couple of questions to ask. We are one of the earlier groups to conduct a randomized study on the effect of off-pump and on-pump techniques in patients with preoperative nondialysis-dependent renal insufficiency undergoing $\mathrm{CABG}$, and our study proved that the off-pump technique is renoprotective in patients with nondialysis-dependent renal insufficiency. As we all know, approximately $15 \%$ to $20 \%$ of the patients undergoing CABG have occult renal dysfunction, meaning they have normal serum creatinine levels (ie, $\leq 1.3 \mathrm{mg} / \mathrm{dL}$ ) in association with decreased glomerular filtration rate (ie, $<60 \mathrm{~mL} / \mathrm{min} / 1.73 \mathrm{~m}^{2}$ body area).

In this study, as you have presented, there is a statistically significant difference in the preoperative serum creatinine levels between the off-pump and on-pump groups. In the OPCAB group, the mean serum creatinine level is $1.3 \mathrm{mg} / \mathrm{dL}$, and in the on-pump CABG group, the serum creatinine level is $1.0 \mathrm{mg} / \mathrm{dL}$. Even a small increase in the preoperative serum creatinine also has a deleterious effect on the postoperative incidence of acute kidney injury.

My question to you is, did you routinely estimate the glomerular filtration rate in these patients? The other question is, what percentage of these patients received aprotinin during their perioperative period to control bleeding?

Dr Elmistekawy. I am sorry, I didn't get your questions.

Dr Sajja. Did you estimate creatinine clearance in these patients? If so, what percentage of the patients in each group had occult renal disease?

Dr Elmistekawy. We did creatinine clearance estimation for the purpose of this study, but otherwise it wasn't routinely done. 
Dr Sajja. Did more patients receive aprotinin in the OPCAB group?

Dr Elmistekawy. I am sorry, I didn't get the question.

Dr Sajja. Is there any difference in the use of aprotinin between the 2 groups?

Dr Elmistekawy. Aprotinin.

Dr Sajja. Use of aprotinin between the 2 groups?

Dr Elmistekawy. We didn't examine this.

Dr Marc Ruel (Ottawa, Ontario, Canada). Perhaps I could intervene. My name is Marc Ruel; I am the senior author of this study. Aprotinin was not used at all in this series except for exceptional cases, for instance, patients receiving clopidogrel during emergency cases, in the old times.

I would like to comment on the findings and respond to some of the excellent questions that have been raised. First, I am an offpump enthusiast and believer. When we started this study, we thought we would actually prove once and for all, in a series with large numbers and good outcomes, that OPCAB is better than CABG on the kidney. Actually, we were surprised to find the complete reverse, in that there was no outcome difference, not only at the univariate level but also at 2 levels of multivariable analysis, even when accounting for preoperative differences in renal function and for comorbidities.

So from this we can think, why do we have those findings? I think Elsayed alluded to the possible institutional or technical factors that may have caused this lack of difference, and one of those factors may be the extra fluid load that patients undergoing CABG receive. A patient undergoing $\mathrm{CABG}$ typically comes out of the operating room with 4 or 5 extra kilos of fluid, and that may in itself be renal protective. On the other hand, we don't have this extra fluid load in OPCAB cases. In addition, OPCAB cases have more ups and downs in terms of their cardiac output during the procedure. They may have short periods of inotrope use, especially when grafting the lateral wall.
Furthermore, maybe one of the reasons we don't see a difference in this study while smaller studies have shown opposite results is that the event rates were overall very low. The results of onpump CABG and OPCAB in this study, even if when including all emergencies, and patients in cardiogenic shock, and patients coming from the catheter laboratory, were very good. So these results clearly show that the perfusion team does an excellent job with those usual, short 1-hour cardiopulmonary bypass time periods needed to do 3 or 4 grafts. Well, with those as a typical, routine case, it is hard to show a difference between off-pump and onpump on the renal outcomes. With this, I would like to acknowledge the excellent questions and comments that have been raised, and thank the Association for the honor of presenting these data.

Dr Massimo Lemma (Milano, Italy). One comment and one question. The comment is that we had a completely different experience. Yesterday I presented the primary end point of the ON-OFF study, where we compared 30-day outcomes of high-risk patients with a euroSCORE greater than 6 after on-pump CABG or OPCAB. In our study, the intention-to-treat analysis showed that there is an advantage for these patients in terms of renal failure, even if not statistically significant, but it became statistically significant after on-treatment analysis, that is, after consideration of crossovers.

The question is related to what you do to maintain hemodynamic stability during the operation. Could you precisely tell us the anesthetic and surgical management of the patient during OPCAB to maintain hemodynamic stability and if you check the cardiac output during the operation?

Dr Elmistekawy. You are right, during exposure, especially of the lateral wall, there is a period of low cardiac output or hypoperfusion, and we optimize this by using vasoactive drugs (eg, norepinephrine) and volume loading, with interruption of the procedure until the blood pressure and the cardiac output are optimized. 